\title{
Bed roughness beneath the Greenland ice sheet
}

\author{
David M. RIPPIN \\ Environment Department, University of York, Heslington, York, UK \\ E-mail: david.rippin@york.ac.uk
}

\begin{abstract}
The roughness of the bed beneath ice streams exerts an important control on their dynamics. Here the first in-depth analysis of roughness beneath the Greenland ice sheet is presented. Much of the interior is underlain by a smooth bed, while the margins are much rougher; this is particularly pronounced in the east where more mountainous topography dominates and fast-flow features are laterally constrained in deep narrow valleys. In contrast, fast flow in the west is much less laterally constrained and areas of high roughness are less extensive and pronounced. It is proposed that there is a major geological control on the distribution of bed variability since a significant thrust-fault coincides approximately with the boundary between rough terrain in the east and the smooth central region. Furthermore there is an abrupt change in roughness approximately coinciding with the crossing of this fault line. This suggests a limiting factor on the extent of fast flow in the east, which is lacking in the west. The size of many glaciers draining Greenland makes their local bed conditions difficult to determine with great confidence. However, the much larger Petermann Glacier lies in a deep trough characterized by a smooth bed that extends some distance into the ice sheet. The smooth bed may be due to deformable marine sediments which facilitate faster flow, although smoothing could also result from ice dynamics and subglacial erosion. That the smooth bed of Petermann Glacier extends some considerable distance raises concerns about the possible stability of this feature, and perhaps others in Greenland too.
\end{abstract}

\section{INTRODUCTION}

The roughness of the terrain beneath ice sheets is an important control on ice flow (Rippin and others, 2011). It is of key concern because the degree of coupling between an ice body and its bed is of fundamental importance in controlling the amount of basal motion experienced by that ice body. This coupling is controlled by bed roughness and subglacial water pressure (Lliboutry, 1987; Willis, 1995). The relationship between subglacial water pressures and basal motion has been explored previously (e.g. Iken, 1981; Bindschadler, 1983; Jansson, 1995; Harper and others, 2007), but there remains a relative dearth of studies concerned with bed roughness due to the many practical difficulties involved in measuring this quantity (Bennett, 2003; Taylor and others, 2004).

The physical importance of characterizing subglacial bed roughness is perhaps best appreciated by considering what controls the dynamics of the fast-flowing ice streams that drain $\sim 90 \%$ of the ice sheets in Antarctica and Greenland. Determining the controls on ice-stream flow is important because the stability of major ice sheets is fundamentally dependent on the behaviour of these ice streams (Bennett, 2003), and is thus key to gaining an understanding of likely past and future changes (Siegert and others, 2004). Particular foci for researching these mechanisms over recent years have been the Siple Coast (e.g. Alley and Bindschadler, 2001; Conway and others, 2002; Wiens and others, 2008) and Rutford Ice Stream (e.g. Doake and others, 2001; Smith and others, 2007), West Antarctica. This research has shown that changes at the ice/bed interface are fundamental for controlling ice flow, but most work in this field to date has focused on the nature of the substrate (e.g. soft or hard bed) and hydrological conditions beneath ice streams, rather than analysing roughness per se. In these studies, the idea of bed roughness is alluded to, but only in relation to the idea of changes in tractional processes, i.e. influences on ice dynamics brought about by the bed substrate and hydrological conditions already mentioned. Alley's idea of 'sticky spots' (Alley, 1993; cf. Stokes and others, 2007), in which localized areas of high basal drag (caused by welldrained till, frozen till or bedrock) are surrounded by larger regions of bed that are well lubricated and thus exhibit a lowshear-stress bed (Alley, 1993; Stokes and others, 2007), is a widely accepted expression of variable bed conditions controlling flow dynamics, but, until relatively recently, pure subglacial roughness has not been dealt with explicitly.

Understanding how roughness variations impact upon ice dynamics relies critically on being able to measure and quantify bed variations beneath ice masses. The role of an irregular bed, and the requirement for sliding ice to move around/over these bed obstacles via the mechanisms of regelation and enhanced ice deformation, has been accepted for some time (Weertman, 1957; Hubbard and Hubbard, 1998). Aside from the role of this small-scale roughness, the first real consideration of bed roughness and its explicit role in ice dynamics was revealed qualitatively by Shabtaie and Bentley (1987) in the Siple Coast region of West Antarctica (cf. Taylor and others, 2004). However, prior to the late 1990s scant attention was paid to developing schemes for determining bed roughness beneath ice bodies quantitatively; a trend partly attributable, at least early on, to the limited availability of widespread radio-echo sounding (RES) data across contemporary ice sheets.

Bed roughness is a quantity that can be derived from RES data, and in recent years, as the availability of such data has increased, analysis of bed roughness has become more common. However, virtually all such analyses to date have been focused on East and West Antarctica (e.g. Taylor and others, 2004; Siegert and others, 2005; Rippin and others, 2006, 2011; Bingham and Siegert, 2007, 2009; Bingham and others, 2007; Li and others, 2010; Ross and others, 2012; Wright and others, 2012). This is most likely because, for many years, extensive RES data were available for Antarctica but not Greenland. This large dataset had its beginnings 
when, between 1967 and 1979, 400 $000 \mathrm{~km}$ of airborne RES data were collected in a joint initiative between the Scott Polar Research Institute (SPRI), University of Cambridge, UK, the US National Science Foundation (NSF) and the Technical University of Denmark (TUD) (e.g. Robin and others, 1977; Drewry, 1983; Siegert, 1999). Since then, data have been collected across Antarctica by a multitude of nations, culminating initially in 2001 in the production of the BEDMAP database (Lythe and others, 2001) and, more recently, BEDMAP2 (Fretwell and others, 2013).

The roughness of a surface can be calculated in many different ways, but by far the most widely developed and applied method for assessing bed roughness is to use fast Fourier transform (FFT) methods to transform bed topography profiles into the frequency domain (e.g. Siegert and others, 2004, 2005; Taylor and others, 2004; Bingham and Siegert, 2007, 2009; Bingham and others, 2007; Rippin and others, 2011; Wright and others, 2012). The method relies on using a FFT to determine the vertical variations of a surface along a horizontal track, and to define these variations in terms of a range of different wavelengths of roughness obstacles (Siegert and others, 2004; cf. Taylor and others, 2004). Usually, the method is applied over a moving window of a given length, the size of which is strongly dependent on sample spacing, such that in studies using the SPRI/NSF/TUD data, the moving window is of the order of 50-100 km wide (e.g. Siegert and others, 2004, 2005; Taylor and others, 2004). Conversely, much higher resolution has been achieved where data are more closely spaced (e.g. window size of $\sim 1 \mathrm{~km}$; cf. Rippin and others, 2011). This is the methodology applied here (more detailed discussion is provided in the next section).

Despite the fairly detailed analyses of Antarctic subglacial roughness, the only analysis of roughness beneath the Earth's other major ice sheet (Greenland) was carried out by Layberry and Bamber (2001) who used, as an indication of the roughness of small-scale bed topography, the root-meansquare (rms) residual bed elevation deviation from a smoothed bed. In doing so, they were able to use this roughness proxy to identify a largely smooth bed in central regions with zones of increased roughness at the margins. Apart from this work, no detailed roughness analysis such as that carried out in Antarctica has been carried out for Greenland. This is surprising, given the importance of basal roughness for understanding flow dynamics (e.g. Rippin and others, 2011), the increasing frequency with which such analyses are carried out in Antarctica, and given concerns about the stability of Greenland under scenarios of climate change, and its potential sea-level contribution (e.g. Rignot and others, 2011). Furthermore, the fact that a large number of RES data exist for Greenland means that an assessment of roughness can be carried out. Here, the first roughness analysis for Greenland is presented.

\section{DATA SOURCES AND METHODOLOGY}

The CReSIS (Center for Remote Sensing of Ice Sheets, University of Kansas, USA) Radar Depth Sounders (RDS) have been used to collect ice thickness data and bed topography beneath Greenland since 1993. Sixteen years of data (including every year from 1993 to 2011 excluding data from 1994, 2000 and 2004, which were not available) were combined to create a dataset of more than $13 \times 10^{6}$ measurements of bed topography (Fig. 1 inset). A number of different instruments have produced these data, and full information on these instruments is available from $\mathrm{ftp}$ ://data.cresis.ku.edu/data/rds/rds_readme.pdf (cf. Gogineni and others, 2001). These data were used to analyse bed roughness, using the FFT approach applied previously in several studies (e.g. Taylor and others, 2004; Bingham and others, 2007; Rippin and others, 2011; Ross and others, 2012).

As stated above, the method relies on using a FFT to determine the vertical variations of a surface along a horizontal track, by transforming bed elevations in a moving window, into the frequency domain, and defining these variations in terms of a range of different wavelengths of roughness obstacles. Overall roughness is then determined as the integral of the relevant power spectra (Siegert and others, 2004; cf. Taylor and others, 2004). Before the FFT approach is used, however, a number of steps are required to prepare the data. The methodology used follows that of Rippin and others (2011) and Ross and others (2012) which is heavily based on that of Taylor and others (2004). The steps followed are described below.

Initially, gaps in bed elevation data must be accounted for. Gaps are not uncommon in RES data, and arise where the bed is not identified by the RES system. This might occur because the bed is very deep or due to intensive scattering within the ice body. Alternatively it might arise because of intermittent failures within the RES system (cf. Rippin and others, 2011). The nature of the FFT approach is such that it requires continuous bed elevation data, and so to enable continuous roughness analysis to take place, where gaps in the input data are small (in this case considered to be $<1 \mathrm{~km}$ along-track distance, which equates to ten sample points), a linear interpolation procedure was used to bridge these gaps. It was considered that interpolation over such a distance was acceptable. However, over greater distances (i.e. where a gap was $>1 \mathrm{~km}$ ), there was considered to be too big a gap over which to interpolate, and so such a gap was classified as a break in the data. Under such circumstances, FFT analysis would recommence further down-profile where there were sufficient continuous data.

The second preparatory stage involved resampling continuous sections of line at a constant step-size. RES data are often collected at semi-regular spacing, but there are often small discrepancies due to variable aircraft speed and changes in course. To facilitate the third preparatory stage, resampling of the bed at a regular step-size of $100 \mathrm{~m}$ was carried out (cf. Rippin and others, 2011; Ross and others 2012).

The final preparatory stage involved subtracting a running mean of the bed topography. This was done to remove largescale variations in topography so that the roughness analysis could more easily focus on smaller-scale variations. A running mean was subtracted over a moving window of 100 sample points, which equates to $10 \mathrm{~km}$. Following Rippin and others (2011), this approach means that roughness is observed over scales that might be considered local as opposed to regional.

Following these preparatory steps, FFT analysis could commence. A FFT was carried out over a window of $3200 \mathrm{~m}$, which is equivalent to $2^{N}$ samples, where $N=5$. It has previously been suggested that this is the minimum value of $N$ that should be used (Brigham, 1988; Taylor and others, 2004; Bingham and others, 2007). It was decided not to use higher values of $N$ as this would mean that the importance of shorter-wavelength roughness would be ignored, which is not desirable (Rippin and others, 2011). The integral of the 


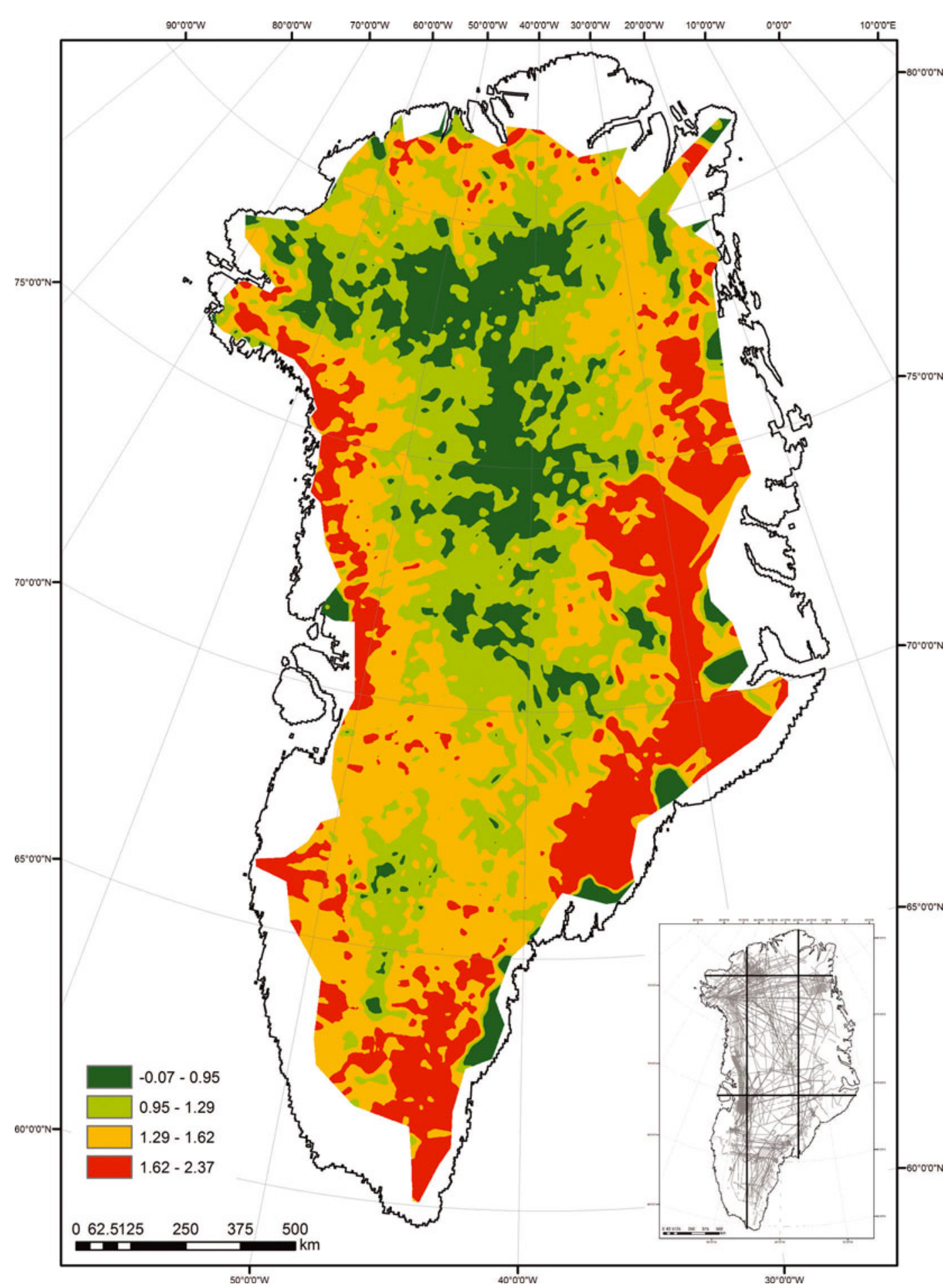

Fig. 1. Bed roughness across the whole of Greenland, where data are available. Roughness is measured as the integral of the FFT calculated over moving windows of $3200 \mathrm{~m}$. These results were then gridded at $1 \mathrm{~km}$, before being smoothed over $10 \mathrm{~km}$. Inset shows the location of survey lines used in the study (we acknowledge the use of data and/or data products from CReSIS generated with support from NSF grant ANT-0424589 and NASA grant NNX10AT68G; cf. Gogineni, 2012), and the thick black lines divide the ice sheet up into nine distinct zones for plotting of the frequency distribution of roughness classes in Figure 2.

resultant FFT of power spectra within each window is finally defined as the bed roughness, and is usually plotted at the centre point of that window (Bingham and Siegert, 2009). Roughness measurements were then interpolated using kriging onto a $1 \mathrm{~km}$ grid, before being smoothed over $10 \mathrm{~km}$.

In addition, roughness was compared with measurements of surface velocity derived using interferometric synthetic aperture radar (InSAR) data from the RADARSAT-1 satellite, collected under the NASA Making Earth Science Data Records for Use in Research Environments (MEaSUREs) project. The data are from 2005-06 (Joughin and others, 2010).

\section{ROUGHNESS ANALYSIS: RESULTS AND INTERPRETATION}

Figure 1 shows bed roughness beneath the whole of the Greenland ice sheet, with (dimensionless) roughness values ranging from -0.07 to 2.37 (note: interpolation extent is limited by data availability). Primary observations indicate 

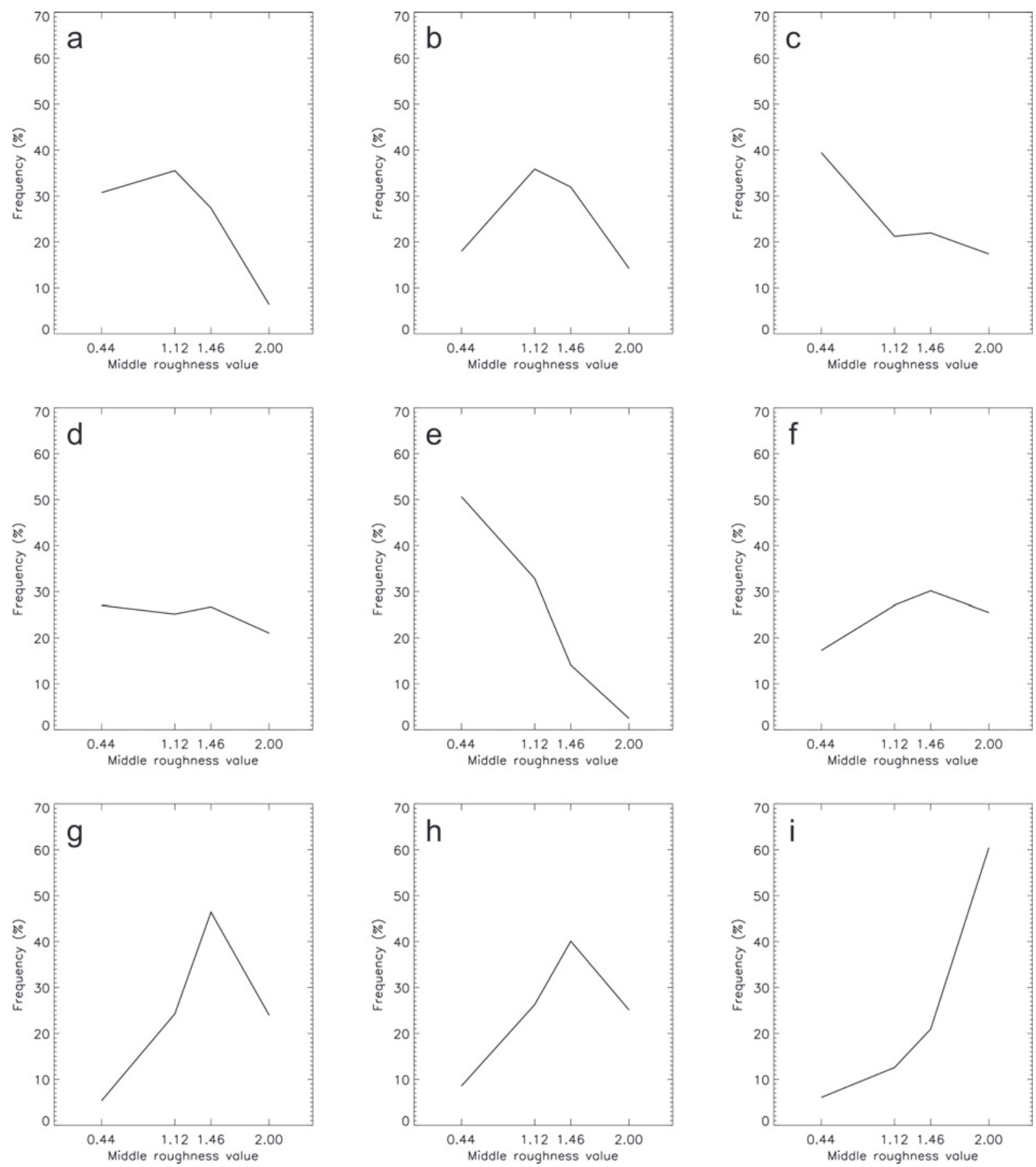

Fig. 2. Frequency distribution of roughness classes across different regions of the ice sheet, derived from raw along-track roughness data. Each chart represents the frequency of values within each of the four classes plotted in Figure 1. $x$-axes display the middle value of roughness in each class (with lower values indicating a smoother bed). $y$-axes show the frequency of values in each class expressed as a percentage of all values in a particular region. Regions are divided into: (a) top-left; (b) top-middle; (c) top-right; (d) middle-left; (e) middle-middle; (f) middle-right; (g) bottom-left; (h) bottom-middle; and (i) bottom-right. The position of each chart is representative of the part of Greenland referred to; the inset to Figure 1 shows the division of the ice sheet into these nine regions.

comparatively low roughness dominates large regions of the interior, whereas the roughness is higher at the margins, and this continues for virtually the entire perimeter. This is further demonstrated by Figure 2 (cf. Fig. 1 inset) which shows a frequency distribution of roughness classes, derived from the raw along-track roughness data. This too indicates that the central region has anomalously low roughness, with higher roughness dominating at the margins (particularly the east). Comparison with the roughness analysis of Layberry and Bamber (2001) reveals good agreement in terms of the spatial extent of rough and smooth areas, i.e. their study also showed a smooth central region and rougher margins. Further comparison with the bed digital elevation model (DEM) of Bamber and others (2001) indicates a strong correlation between basal topography and bed roughness, such that where bed topography is higher, there is generally elevated roughness (cf. Figs 1 and 3). Conversely, in the central region of the ice sheet, it is deeper, and lower roughness dominates.

There is clearly therefore a significant distinction to be made between two regimes: those marginal areas where roughness is high, and the central region where roughness is much lower. Taking this division further, it is apparent that 


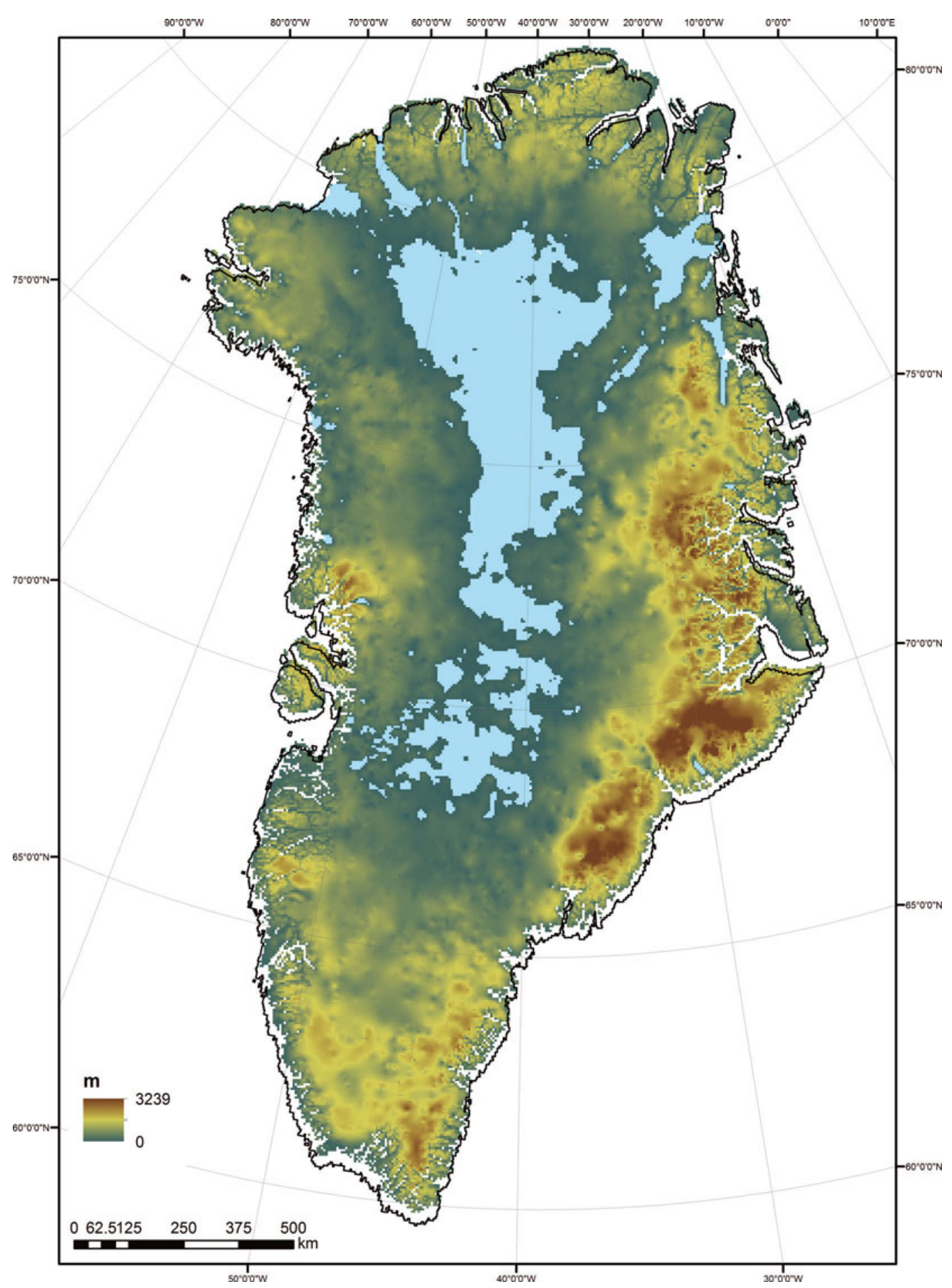

Fig. 3. Bed topography DEM acquired as part of the Program for Arctic Regional Climate Assessment (PARCA) with a $5 \mathrm{~km}$ grid spacing (after Bamber, 2001; Bamber and others, 2001, 2003). Area shaded purple is where the elevation is below sea level (after Bamber and others, 2003, fig. 3).

the roughest terrain is to be found on both the eastern and western margins, with the most extensive and pronounced zone of high roughness found on the eastern side of the ice sheet.

Elevated bed roughness is more pronounced and more extensive in the east, reflecting the existence of more mountainous terrain here. Here fast-flowing features lie in well-constrained valleys, so bed topography exerts a profound effect on the form of fast flow (Fig. 4). In the west, fast flow is much less well constrained and appears more sprawling, in keeping with the comparatively less extensive and pronounced roughness here (cf. Bamber and others, 2000; Joughin and others, 2010). This lack of constraint arises because bedrock topography is much less pronounced here, and so it does not provide such rigid limits to the lateral spreading of ice streams. Siegert and others (2004) also identified little resistance from subglacial topography at the margins of the Siple Coast ice streams, and suggested that this means these features could relatively easily migrate laterally. Such reduced control by bedrock topography is also exerted here. These results support the conclusions of Bamber and others (2000) who observed the flow regime in the west was 


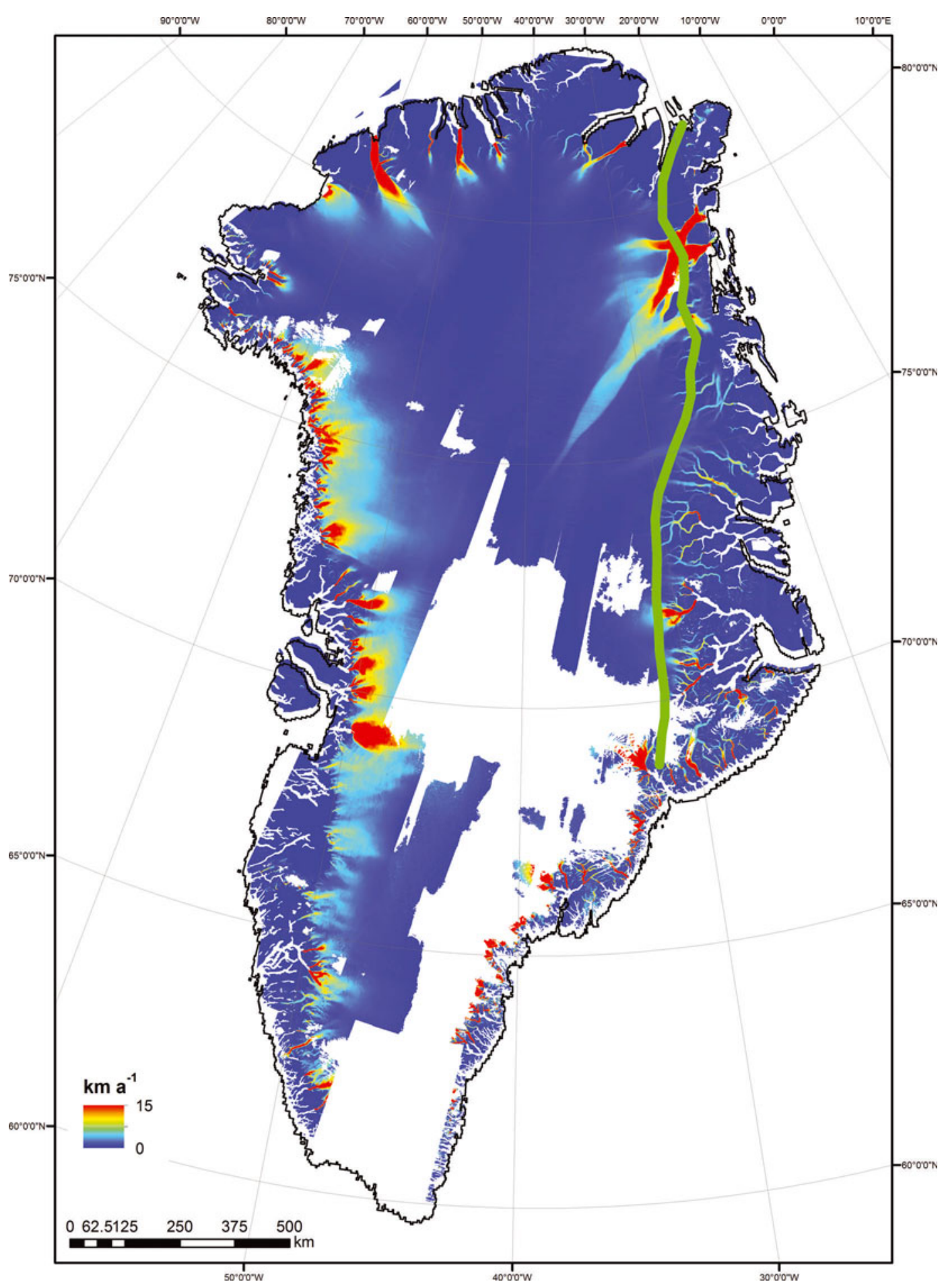

Fig. 4. Ice velocity data for winter 2005/06, acquired from RADARSAT-1 InSAR data from the US National Snow and Ice Data Center (NSIDC) (Joughin and others, 2013). Overlain is the approximate location of a major thrust fault (thick green line; Dawes, 2009).

so different to that elsewhere that it 'must reflect a fundamental difference between the continental margins on the west coast and those elsewhere' (p. 71). The current analysis presented here strongly supports this suggestion, in identifying distinct differences between the rough terrain found in the west and that found in the east. It also indicates that the identified lack of constraining topography on the west coast actually extends a great distance into the ice sheet, and dominates much of the subglacial topography under the entire ice sheet.

These results therefore suggest a very distinct sub-ice boundary that perhaps separates the roughest terrain in the east from the rest of the ice sheet. Coincident with the distinct eastern boundary between rough and smooth bed is the limit of the inland extent of fast flow (cf. Figs 1 and 4). Unfortunately the geology of the subglacial topography beneath the Greenland ice sheet is poorly known. However, Dawes (2009, fig. 1) shows the presence of a significant north-south-trending thrust fault in East Greenland (Fig. 4). The location of this fault approximately defines part of the boundary between smooth and rough bed topography, suggesting that there may be an important geological control (cf. Fig. 1). This fault marks a boundary between rocks to the east that are primarily associated with Devonian and 


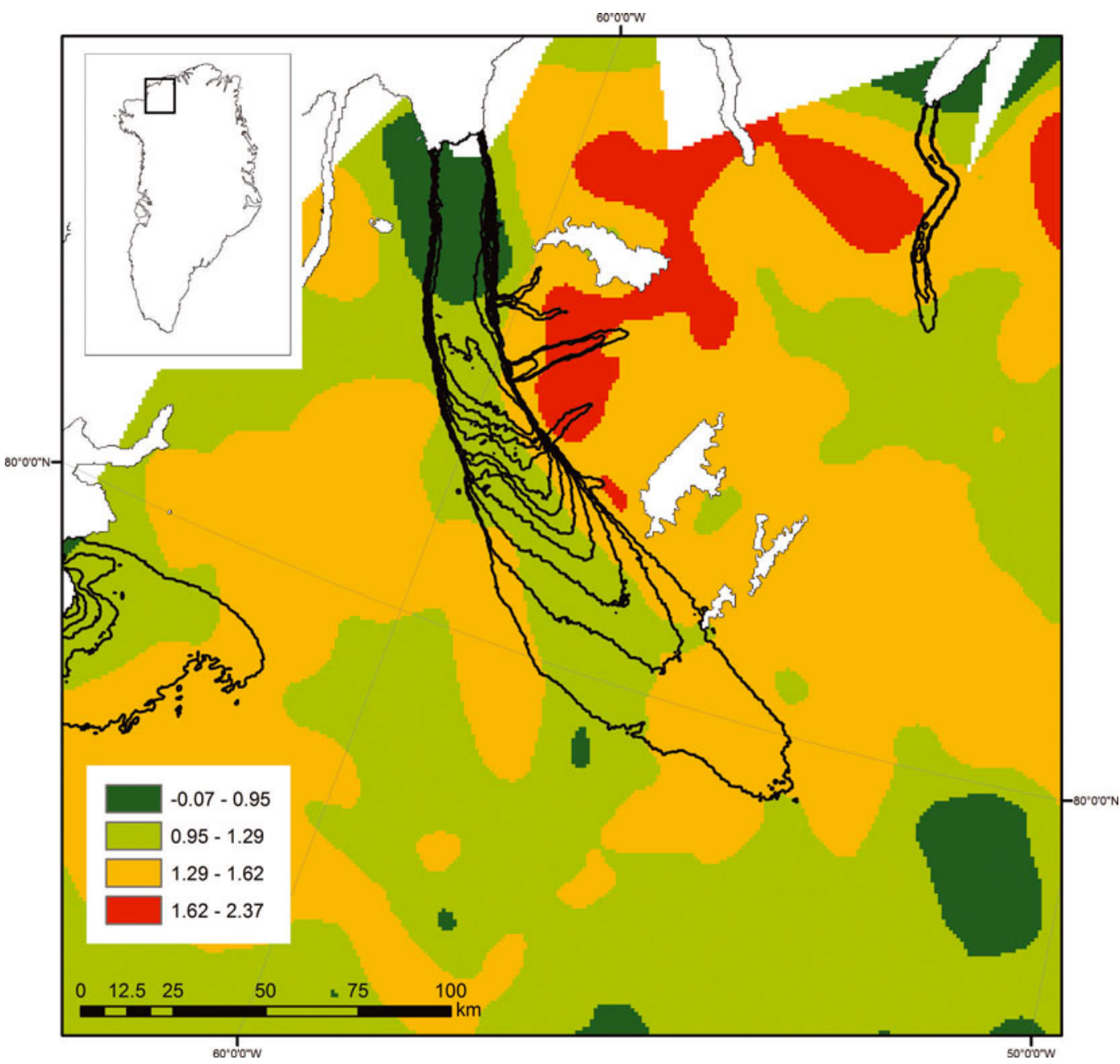

Fig. 5. The roughness of Petermann Glacier with contours of velocity (cf. Fig. 3) overlain. Areas shaded white indicate no velocity data. Note how the main trunk of Petermann Glacier follows an area of low roughness.

Silurian fold belts ( 443-359 Ma BP), as well as basins of primarily Cambrian to Silurian age ( 542-416 Ma BP). By contrast, to the west of this fault, Dawes (2009) suggests that Mesoproterozoic sub-ice basins (1600-1000 Ma BP) may well largely dominate, along with Precambrian Shield (older than $600 \mathrm{MaBP})$. Although Greenland geology is poorly known, this brief analysis suggests that the roughest terrain in the east may well be a consequence of younger rock formations, whereas the smoother bed beneath to the west of this, and perhaps beneath much of the ice sheet, may be related to much older rocks, i.e. terrain that is older and which has therefore undergone more erosion.

The link between a smooth bed and faster ice flow is an important one. Where a smooth bed has been identified from roughness studies of Antarctica, a common explanation is that it is the result of the presence of marine sediments that fill in the gaps between bedrock obstacles. In such situations in Antarctica, the presence of sediments is often attributed to the potential that parts of the terrain beneath contemporary ice sheets may be grounded below sea level, thus enabling the emplacement of marine sediments (cf. Scherer and others, 1998; Rippin and others, 2006; Bingham and Siegert, 2009; Pollard and DeConto, 2009). Another possible explanation is that such sediments could be a result of in situ erosion caused by basal motion, and so in this way the occurrence of basal motion results in the smoothing of bed obstacles. Finally, any sediments could also have been transported from upstream locations or could have resulted from deposition in environments before the ice sheet was in place, such as lake or fluvial settings (Rippin and others, 2006). It seems highly likely that, in reality, feedbacks exist between the process and the outcome (cf. Rippin and others, 2006), but, with no data other than roughness information, the processes involved and the nature of the environment remain speculative. In light of these theories it is striking that in this study of Greenland, at the margins, where the fastestflowing ice exists, the bed is rougher than the inland region. However, at the smaller scale, among the many smaller fastflow features along the east and west coasts of Greenland, there is some evidence that they may follow valleys of reduced basal roughness. However, this is not conclusive due to: (1) their comparatively small size; (2) the sometimes limited radar data; and (3) the relatively large scale over which roughness is calculated.

It is beyond the scope of this paper to analyse in detail the roughness of the bed beneath Greenland's individual fastflow features. However, by way of example, the nature of the bed beneath Petermann Glacier is now dealt with. Petermann Glacier is located in northwest Greenland. This feature has received extensive attention of late due to a large calving event that occurred in 2010 (Nick and others, 2012). There are also a large number of RES data available here, which makes more in-depth analysis possible. Petermann Glacier lies in a deep subglacial trough, flanked by steep 
valley sides. High velocities extend to deep within the ice sheet, where the bed is largely well below sea level (Fig. 5). The analysis of roughness presented here reveals a strikingly smooth bed in association with Petermann Glacier's entire length, bounded laterally by regions of higher roughness. Such lateral constraint is particularly marked in the lower reaches, yet towards its upper reaches the glacier extends into a region where the bed appears to open out and the lateral constraints of high roughness are lost. In other words, it is potentially fed by a very large area of the ice sheet which is underlain by a smooth bed.

The concept of marine sediment emplacement with respect to Greenland is not a widely held consideration, yet the smooth bed of Petermann Glacier is well below sea level (Nick and others, 2012), and Bamber and others (2003) also showed that there is an extensive depression in the centre of Greenland, as a consequence of isostatic depression. Although marine inundation before emplacement of the ice sheet may be possible in the case of Petermann Glacier, thus explaining the smooth bed here, this seems unlikely for Greenland more generally, as isostatic rebound would likely result in the terrain being above sea level, and so marine sediments may not be responsible for the smooth bed more widely. Another alternative that is important to consider is the role of ice dynamics and subglacial erosion. The pronounced trough in which Petermann Glacier lies will readily act to channelize ice along it, and this enhanced rate of ice flow would then serve to smooth the smaller-scale features within it. It is difficult to state how representative Petermann Glacier might be, since it is one of the largest outlets in Greenland and, unusually for such a large Greenlandic glacier, it loses a major proportion of its mass from its tongue through submarine melting (Rignot and others, 2001; Nick and others, 2012). It is therefore apparent that carrying out similar, more detailed investigations into the significance of the roughness of other Greenland glaciers and ice streams is to be strongly encouraged.

\section{CONCLUSIONS}

The first full assessment of the basal roughness beneath the Greenland ice sheet has been presented, in which a pronounced difference has been identified between the much rougher margins and the much smoother internal regions, which are characterized by a uniformly much smoother bed. There are also pronounced differences between conditions on the eastern and western sides of the ice sheet. High roughness in the east is associated with fastflow features that are well constrained by topography. In the west, roughness is less pronounced, and this is reflected in the fast-flow features here displaying far less lateral control. It is possible that marine sediments may be at least in part responsible for the smoothing observed in central regions, but this needs further investigation. Although a glacier-byglacier approach is beyond the scope of this paper, a preliminary investigation of Petermann Glacier reveals it to be underlain by a very smooth bed, which extends some considerable distance into the ice sheet. This raises potential concerns about long-term future changes in the ice sheet, and the potential for large regions of the ice sheet to be drained through Petermann Glacier. This study also highlights the importance of basal roughness as a control on ice dynamics, and should be taken into consideration in future studies of the stability of the Greenland ice sheet.

\section{ACKNOWLEDGEMENTS}

Data were provided by the Distributed Active Archive Center, US National Snow and Ice Data Center, University of Colorado, Boulder, CO. Data and data products were also provided by CReSIS, generated with support from NSF grant ANT-0424589 and NASA grant NNX10AT68G. I thank two anonymous reviewers for their comments and insights that substantially helped to improve the paper.

\section{REFERENCES}

Alley RB (1993) In search of ice-stream sticky spots. J. Glaciol., 39(133), 447-454

Alley RB and Bindschadler RA eds. (2001) The West Antarctic ice sheet: behavior and environment. (Antarctic Research Series 77) American Geophysical Union, Washington, DC

Bamber J (2001) Greenland 5 km DEM, ice thickness, and bedrock elevation grids. National Snow and Ice Data Center, Boulder, CO. Digital media: http://nsidc.org/data/nsidc-0092.html

Bamber JL, Hardy RJ and Joughin I (2000) An analysis of balance velocities over the Greenland ice sheet and comparison with synthetic aperture radar interferometry. J. Glaciol., 46(152), 67-74 (doi: 10.3189/172756500781833412)

Bamber JL, Layberry RL and Gogineni SP (2001) A new ice thickness and bed data set for the Greenland ice sheet. 1. Measurement, data reduction, and errors. J. Geophys. Res., 106(D24), 33 773-33 780 (doi: 10.1029/2001JD900054)

Bamber JL, Baldwin DJ and Gogineni SP (2003) A new bedrock and surface elevation dataset for modelling the Greenland ice sheet. Ann. Glaciol., 37, 351-356 (doi: 10.3189/ 172756403781815456)

Bennett MR (2003) Ice streams as the arteries of an ice sheet: their mechanics, stability and significance. Earth-Sci. Rev., 61(3-4), 309-339 (doi: 10.1016/S0012-8252(02)00130-7)

Bindschadler R (1983) The importance of pressurized subglacial water in separation and sliding at the glacier bed. J. Glaciol., 29(101), 3-19

Bingham RG and Siegert MJ (2007) Radar-derived bed roughness characterization of Institute and Möller ice streams, West Antarctica, and comparison with Siple Coast ice streams. Geophys. Res. Lett., 34(21), L21504 (doi: 10.1029/ 2007GL031483)

Bingham RG and Siegert MJ (2009) Quantifying subglacial bed roughness in Antarctica: implications for ice-sheet dynamics and history. Quat. Sci. Rev., 28(3-4), 223-236 (doi: 10.1016/ j.quascirev.2008.10.014)

Bingham RG, Siegert MJ, Young DA and Blankenship DD (2007) Organized flow from the South Pole to the Filchner-Ronne ice shelf: an assessment of balance velocities in interior East Antarctica using radio echo sounding data. J. Geophys. Res., 112(F3), F03S26 (doi: 10.1029/2006JF000556)

Brigham EO (1988) Fast Fourier transform and its applications. Prentice Hall, Upper Saddle River, NJ

Conway H, Catania G, Raymond C, Scambos T, Engelhardt H and Gades A (2002) Switch of flow direction in an Antarctic ice stream. Nature, 419(6906), 465-467 (doi: 10.1038/nature01081)

Dawes PR (2009) The bedrock geology under the Inland Ice: the next major challenge for Greenland mapping. Geol. Surv. Den. Greenl. Bull., 17, 57-60

Doake CSM and 7 others (2001) Rutford Ice Stream, Antarctica. In Alley RB and Bindschadler RA eds. The West Antarctic ice sheet: behavior and environment. (Antarctic Research Series 77) American Geophysical Union, Washington, DC, 221-235

Drewry DJ (1983) Antarctica: glaciological and geophysical folio. Scott Polar Research Institute, Cambridge

Fretwell P and 55 others (2013) Bedmap2: improved ice bed, surface and thickness datasets for Antarctica. Cryosphere, 7, 375-393 (doi: 10.5194/tc-7-375-2013) 
Gogineni P (2012) CReSIS data. Center for Remote Sensing of Ice Sheets, Lawrence, KS. Digital media: http://data.cresis.ku.edu/

Gogineni S and 9 others (2001) Coherent radar ice thickness measurements over the Greenland ice sheet. J. Geophys. Res., 106(D24), 33 761-33 772

Harper JT, Humphrey NF, Pfeffer WT and Lazar B (2007) Two modes of accelerated glacier sliding related to water. Geophys. Res. Lett., 34(12), L12503 (doi: 10.1029/2007GL030233)

Hubbard B and Hubbard A (1998) Bedrock surface roughness and the distribution of subglacially precipitated carbonate deposits: implications for formation at Glacier de Tsanfleuron, Switzerland. Earth Surf. Process. Landf., 23(3), 261-270

Iken A (1981) The effect of the subglacial water pressure on the sliding velocity of a glacier in an idealized numerical model. J. Glaciol., 27(97), 407-421

Jansson P (1995) Water pressure and basal sliding on Storglaciären, northern Sweden. J. Glaciol., 41(138), 232-240

Joughin I, Smith B, Howat IM, Scambos T and Moon T (2010) MEASUREs Greenland ice sheet velocity map from InSAR data. National Snow and Ice Data Center, Boulder, CO. Digital media: http://nsidc.org/data/docs/measures/nsidc0478_joughin

Layberry RL and Bamber JL (2001) A new ice thickness and bed data set for the Greenland ice sheet. 2. Relationship between dynamics and basal topography. J. Geophys. Res., 106(D24), 33 781-33 788 (doi: 10.1029/2001JD900053)

Li X and 7 others (2010) Characterization of subglacial landscapes by a two-parameter roughness index. J. Glaciol., 56(199), 831-836 (doi: 10.3189/002214310794457326)

Lliboutry L (1987) Realistic, yet simple bottom boundary conditions for glaciers and ice sheets. J. Geophys. Res., 92(B9), 9101-9109 (doi: 10.1029/JB092iB09p09101)

Lythe MB, Vaughan DG and BEDMAP consortium (2001) BEDMAP: a new ice thickness and subglacial topographic model of Antarctica. J. Geophys. Res., 106(B6), 11 335-11 351 (doi: 10.1029/ 2000JB900449)

Nick FM and 8 others (2012) The response of Petermann Glacier, Greenland, to large calving events, and its future stability in the context of atmospheric and oceanic warming. J. Glaciol., 58(208), 229-239 (doi: 10.3189/2012JoG11J242)

Pollard D and DeConto RM (2009) Modelling West Antarctic ice sheet growth and collapse through the past five million years. Nature, 458(7236), 329-332 (doi: 10.1038/nature07809)

Rignot E, Gogineni S, Joughin I and Krabill W (2001) Contribution to the glaciology of northern Greenland from satellite radar interferometry. J. Geophys. Res., 106(D24), 34 007-34 019 (doi: 10.1029/2001JD900071)

Rignot E, Velicogna I, Van den Broeke MR, Monaghan A and Lenaerts J (2011) Acceleration of the contribution of the Greenland and Antarctic ice sheets to sea level rise. Geophys. Res. Lett., 38(5), L05503 (doi: 10.1029/2011GL046583)

Rippin DM, Bamber JL, Siegert MJ, Vaughan DG and Corr HFJ (2006) Basal conditions beneath enhanced-flow tributaries of
Slessor Glacier, East Antarctica. J. Glaciol., 52(179), 481-490 (doi: 10.3189/172756506781828467)

Rippin D, Vaughan DG and Corr HFJ (2011) The basal roughness of Pine Island Glacier, West Antarctica. J. Glaciol., 57(201), 67-76 (doi: 10.3189/002214311795306574)

Robin GdeQ, Drewry DJ and Meldrum DT (1977) International studies of ice sheet and bedrock. Philos. Trans. R. Soc., Ser. B, 279(963), 185-196

Ross N and 9 others (2012) Steep reverse bed slope at the grounding line of the Weddell Sea sector in West Antarctica. Nature Geosci., 5(6), 393-396 (doi: 10.1038/ngeo1468)

Scherer RP, Aldahan A, Tulaczyk S, Possnert G, Engelhardt H and Kamb B (1998) Pleistocene collapse of the West Antarctic ice sheet. Science, 281(5373), 82-85 (doi: 10.1126/science. 281.5373.82)

Shabtaie S and Bentley CR (1987) West Antarctic ice streams draining into the Ross Ice Shelf: configuration and mass balance. J. Geophys. Res., 92(B2), 1311-1336 (doi: 10.1029/ JB092iB02p01311)

Siegert MJ (1999) On the origin, nature and uses of Antarctic icesheet radio-echo layering. Progr. Phys. Geogr., 23(2), 159-179 (doi: 10.1177/030913339902300201)

Siegert MJ, Taylor J, Payne AJ and Hubbard B (2004) Macro-scale bed roughness of the Siple Coast ice streams in West Antarctica. Earth Surf. Process. Landf., 29(13), 1591-1596 (doi: 10.1002/esp.1100)

Siegert MJ, Taylor J and Payne AJ (2005) Spectral roughness of subglacial topography and implications for former ice-sheet dynamics in East Antarctica. Global Planet. Change, 45(1-3), 249-263 (doi: 10.1016/j.gloplacha.2004.09.008)

Smith AM and 6 others (2007) Rapid erosion, drumlin formation and changing hydrology beneath an Antarctic ice stream. Geology, 35(2), 127-130 (doi: 10.1130/G23036A.1)

Stokes CR, Clark CD, Lian OB and Tulaczyk S (2007) Ice stream sticky spots: a review of their identification and influence beneath contemporary and palaeo-ice streams. Earth-Sci. Rev., 81(3-4), 217-249 (doi: 10.1016/j.earscirev.2007.01.002)

Taylor J, Siegert MJ, Payne AJ and Hubbard B (2004) Regional-scale roughness beneath ice masses: measurement and analysis. Comput. Geosci., 30(8), 899-908 (doi: 10.1016/j.cageo. 2004.06.007)

Weertman J (1957) On the sliding of glaciers. J. Glaciol., 3(21), 33-38

Wiens DA, Anandakrishnan S, Winberry JP and King MA (2008) Simultaneous teleseismic and geodetic observations of the stick-slip motion of an Antarctic ice stream. Nature, 453(7196), 770-774 (doi: 10.1038/nature06990)

Willis IC (1995) Intra-annual variations in glacier motion: a review. Progr. Phys. Geogr., 19(1), 61-106 (doi: 10.1177/ 030913339501900104)

Wright AP and 12 others (2012) Evidence of a hydrological connection between the ice divide and ice sheet margin in the Aurora Subglacial Basin, East Antarctica. J. Geophys. Res., 117(F1), F01033 (doi: 10.1029/2011JF002066) 